\title{
Sustainability and Emerging Concrete Materials and Their Relevance to the Middle East
}

\author{
Obada Kayali $^{{ }^{*}}$, M. Naseer Haque ${ }^{2}$ and Jamal M. Khatib ${ }^{3}$ \\ ${ }^{I}$ School of Aerospace, Civil and Mechanical Engineering, University of New South Wales@ ADFA, Canberra, Austra- \\ lia; ${ }^{2}$ Department of Civil Engineering, College of Engineering and Petroleum, University of Kuwait, Kuwait; ${ }^{3}$ School of \\ Engineering and the Built Environment, University of Wolverhampton, Wolverhampton, WV1 1SB, UK
}

\begin{abstract}
Judicial use of cement coupled with the beneficial employment of certain so called 'industrial waste products' constitute the backbone of a sustainable concrete technology. The use of fly ash, ground granulated blast furnace slag (GGBFS), rice husk ash, condensed silica fume (CSF), metakaolin and recycled concrete, bricks and other materials are all gaining varying degrees of acceptance from engineers and the society. Careful design that considers long-term durability coupled with the use of 'waste' materials other than cement and natural aggregates can further enhance the sustainability of structures. High performance concrete (HPC) which is becoming the concrete of choice for rapidly emerging new and strong economies, can provide the opportunity for sustainable design and material use. The inclusion of industrial byproducts in the production of high-strength-high-performance concrete is a significant contribution to sustainable industry. As research publications abound with results showing benefits of certain materials whether from waste products or otherwise, it is the duty of the engineer to judge whether one or all of such materials should be used. A judgment, as this, needs to be based on the particular circumstances that dominate the building in question.
\end{abstract}

Keywords: Cement, $\mathrm{CO}_{2}$, Concrete, Durability, Fly Ash, Geopolymers, Green House Gases, Metakaolin, Silica Fume, Slag, Sustainability.

\section{INTRODUCTION}

Sustainability is a new dominant paradigm shift in Engineering and is pointing the way of the future. Among major concerns of sustainability is the fragility of the natural environment. Its aim in this regard is to arrest the negative impact of human activity. In its general meaning, sustainability embodies all the provisions necessary for excellent engineering solutions. Such solutions are those that contribute in a balanced measure to profitability, long-term community benefits and low environmental impact.

In this paper, the authors identify the issues that concern sustainability in the concrete industry. The authors then introduce and discuss the areas where the quest for sustainability can take a substantial advantage. The authors hope that the conclusions of this article will be heeded by those involved in the building industry especially at this time of extraordinary heated activity of concrete construction in the Middle East.

\section{DEFINITION OF SUSTAINABILITY}

Rather than leave this term subject to different perceptions, it is preferred that a definition, broad as it may be, should be able to limit the scope in the argument for sustainability, and especially as far as building activities are concerned.

*Address correspondence to this author at the School of Aerospace, Civil and Mechanical Engineering, University of New South Wales at The Australian Defence Force Academy, Canberra, ACT 2600, Australia; Tel: +61 2 62688329; Fax: +61 2 62688337; E-mail: o.kayali@adfa.edu.au
Dictionaries give the meaning of sustainability as the ability to be maintained. Dictionaries further define the term in ecological perspective as 'exploiting natural resources without destroying the ecological balance of an area'.

These definitions very well describe the problem that we are facing in the concrete industry. The questions that are presented in this regard are:

Can the concrete industry be maintained at the same pace that it is doing now?

Can this industry be controlled to certain defined limits by which the ecological balances are maintained?

To discuss and then attempt to answer these questions, we need to examine certain facts. These facts relate to the particular concrete industry.

\section{CEMENT PRODUCTION}

It is estimated that in the year $1900,10 \mathrm{Mt}\left(10 \times 10^{6}\right.$ tonnes) of cement were produced globally. This quantity is estimated to have produced $40 \mathrm{M}$ cubic metres of concrete [1]. It is estimated that the world population in 1900 was 1.650 billion. That is $0.024 \mathrm{~m}^{3}$ of concrete was the average per person. In contrast, a 2004 estimate puts cement production at $1.7 \times 10^{9}$ tonnes per year [2], producing 6 billion $\mathrm{m}^{3}$. That is at the average of $1 \mathrm{~m}^{3}$ per person. Cement production has increased by 170 times. World population has increased by 3.9 times. The average cement consumption of each person on Earth has increased from $6.25 \mathrm{~kg}$ per year to $268 \mathrm{~kg}$ per year. The average concrete consumption per person increased, by approximately 42 times. Aitcin has cited 
Scheubel and Nachtwey [3] who did a very interesting study relating the consumption of cement to the per capita income. They found that cement consumption peaks at $600 \mathrm{~kg}$ per capita when the income is at US $\$ 10,000$ to US $\$ 13,000$ per capita. Cement consumption declines for the increased income after that. Since the increase in consumption is rapid within the lower income categories, it is therefore expected that it is the emerging economies, in other words, the developing countries, that will lead consumption figures. This, of course is an extremely interesting phenomenon of socioeconomic dimensions, but it is beyond the scope of this paper.

To date, information from the cement industry in the UAE, one of the Middle Eastern countries, illustrates that cement grinding capacity will surge by about $37 \%$ in 2007 and by an even higher $51 \%$ in 2008 , settling at 35.4 million tons per annum, prior to leaping a further $14 \%$ in 2009 to record 40.5 million tons per annum[4].

The UAE currently faces a shortage of cement production by about 5 million tonnes per year with a current production capacity of 11 million tonnes per annum which is estimated to have increased by 3 to 4 million tonnes per annum in 2007. According to a report, the estimated consumption of cement in the Arabian Gulf countries is more than 40 million tonnes and would increase tremendously in the next three years as the investment in key sectors will be around \$ 8 billion in the years 2006-2009 [5]. In 2005, cement consumption in the UAE was $14 \mathrm{Mt}$, at the rate of $2920 \mathrm{~kg}$ per capita. This is more than 10 times the average world consumption [6].

The amount of $\mathrm{CO}_{2}$ emission from cement industry varies between 0.82 tonnes per tonne of cement, when the estimate is made by those from within the industry itself $[2,7]$ to 1 tonne $\mathrm{CO}_{2}$ per tonne of cement, when the estimate is made by other researchers [8]. It is however certain that $\mathrm{CO}_{2}$ emission that is produced from cement manufacture exceeds 0.82 tonnes per tonne of cement. There are estimates that $\mathrm{CO}_{2}$ emissions from cement manufacture alone amount to $10 \%$ of the greenhouse gases (GHG) [9]. Much less pessimistic studies put this figure at $5 \%$ [10].

In 2002, the World Business Council for Sustainable Development, (WBCSD) recommended the reduction of $\mathrm{CO}_{2}$ emissions from cement manufacture processes by $30 \%$ by 2020 and by $60 \%$ by 2050 [11]. A study by Eco Securities made for the United Nations Environment Programme Finance Initiative [12] placed cement industry in the high risk category when it comes to the impact of climate change and GHG emission policies on the industry and thus on lending institutions. Holdren, has found that stabilizing the atmospheric concentration of $\mathrm{CO}_{2}$ requires reduction in $\mathrm{CO}_{2}$ emission to a fraction of today's. The moderate projection of global $\mathrm{CO}_{2}$ emission is that by the year 2100 it will reach 20 $\mathrm{GtC}$ (gigatons of carbon) per year [13]. Holdren postulated that stabilizing atmospheric $\mathrm{CO}_{2}$ will need to have a target of about $7 \mathrm{GtC}$ per year by the year 2100 . This target and the maintenance of a steady decline rate may eventually lead to an ideal target of 3-4 GtC by the year 2200. That level would only bring back the level of $\mathrm{CO}_{2}$ in the atmosphere to that of twice the level of pre-industrial concentration.

\section{THE SHARE OF CONCRETE PRODUCTION}

According to the report of the US Department of Energy, concrete production accounts to $12 \%$ of the $\mathrm{CO}_{2}$ emissions associated with cement and concrete industry [14]. Therefore, one should always add such figure to the figures allocated for cement production alone. The factors contributing to this are mainly, quarrying and transportation of aggregates and the rest of the manufacturing processes and transportation of finished product. It is of interest to note that the report also shows that cement and concrete industry in the United States operates at only $40 \%$ thermal efficiency.

From all of this, it can be concluded that:

- cement manufacture and concrete production is a major contributor to GHG (green house gases) emissions.

- the level of $\mathrm{CO}_{2}$ emission as contributed by the cement industry is not sustainable.

- measures must be taken by the industry to address this issue and drastically reduce the $\mathrm{CO}_{2}$ share of cement and concrete.

- democratic governments, under various national and international influences are implementing policies that will enforce reductions in GHG emissions.

- cement and concrete industry groups will have to heavily invest in R\&D in order to be able to meet minimum targets of reductions while staying viable as profit generating ventures.

\section{SO, WHAT CAN BE DONE?}

The finding that has been mentioned above regarding the inefficiency of cement and concrete manufacturing is of course of extreme importance. However, this discussion will only be limited to other aspects in the raw materials of concrete and to the aspects of the finished product. These aspects, we believe, are what we as concrete and structural practitioners can focus on in order to contribute towards the aim of reducing GHG emissions. The following paragraphs include brief identification of such aspects.

\section{Creation of Durable Concrete}

The Romans used all natural cementitious materials to build concrete roads, concrete water aqueducts, amphitheatres, temples and bridges. Many of their structures are still used till this day for very much the same purpose [15]. The Roman Empire stretched over many climates, yet their concrete was durable. It withstood freezing and thawing cycles as well as alkali-aggregate reactions. It was not high-strength concrete, but it certainly was and still is high performance concrete.

Building with durable concrete means not to have to rebuild again and not to need more cement. This is apart from the savings made on repair and all the indirect sources of $\mathrm{CO}_{2}$ emission that result from employing such activities. But may be we need to go a bit further in being inspired by the ancient Romans. One of the reasons for their concrete lasting such a very long time is that it did not contain steel reinforcing rods. Another reason is the fact that they often used small pre-cast elements, sometimes with crude shape and some- 
times with perfectly molded shapes and sizes. Such practice created concrete that resisted cracking due to temperature and humidity changes. Had they used steel bar reinforcement, they would have had to increase the strength of their concrete and thus reduce its permeability. They would have employed large elements, and eventually would have got similar problems to what we have today.

\section{The Questions Here are:}

Are we ready to rethink some of our practices that are being taken for granted? Can we re-invent concrete practices such that we depend more on small, lightweight and unreinforced elements? The authors believe we can, provided that people in several important and related institutions work consciously together towards this purpose. These include the architects, the structural engineers, the academics, the contractors, the legislatives, and other relevant government bodies together with certain national and international organizations.

But, even if we did not introduce such a drastic change, we need to look at our practices whose consequences are detrimental to durability.

Many good ready mix concrete firms suffer from the common problem of variability of results. The first author happened to assist researching this problem and found out a great deal of reliance on concrete-mystery thinking. That is, that the concrete will somehow be fine no matter what. Day to day variation in grading, moisture content and type of aggregate affect workability which often gets treated by an operator's quick decision, often increasing the water content to the detriment of durability characteristics.

Steel reinforcement is another major area where attention must be given. In particular, attention should be given to the detailing. The congestion of bars and the availability of adequate cover are extremely important aspects that can not be ignored. Detailing must not be left to the site foreman to sort out. Such a practice often leads to very little or absolutely no cover. The result would be accelerated deterioration and often great repair cost or even demolition and rebuilding.

\section{Using Less Cement}

In 1980, Bryant Mather published an article in Concrete International titled "Use Less Cement" [16], in which he warned against the effects of too much cement in mass concrete that can cause thermal stresses. In 2000, he published another article under the same title. In the latter, Mather pointed out the fact that even in sections like pavements and bridge decks, too much cement content causes increased cracking due to shrinkage and thermal effects [17]. He further demonstrated that if strength was not required for load carrying capacity, then other problems of durability may be addressed by different means suitable for the particular durability issue.

The idea that strength will cover all possible issues and faults is a mistaken one. A student of the first author once requested a contractor to supply him with a $32 \mathrm{MPa}$ concrete for a research that needed a large pour. When the results came out he discovered that the concrete was a $55 \mathrm{MPa}$ grade. When the student informed the 'reputable' contractor of the results, the contractor was proud of the fact that he usually gets much more than the target. Some contractors find it easier and cheaper to give much higher strengths than to be dragged into disputes later on. No wonder we have cracks in the concrete.

\section{Replacing a Small or Large Portion of Cement with other Supplementary Cementitious Materials}

Nowadays, there are several powdery materials that fit into this category. To limit the scope of this paper, we will focus on a limited number of materials that have gained a great deal of popularity in recent years. These are: condensed silica fume, fly ash, ground granulated blast furnace slag, metakaolin and rice husk ash.

Without going into great details about the properties and characteristics of these materials, we will briefly highlight certain points regarding each.

\section{Condensed Silica Fume}

Silica fume is a byproduct of the reduction of high-purity quartz with coal in electric furnaces in the production of silicon and ferrosilicon alloys. Silica fume consists of very fine particles with a surface area in the order of $20,000 \mathrm{~m}^{2} / \mathrm{kg}$. On average its particles are approximately 100 times smaller than cement particles. Its extreme fineness and high silica content make it a highly effective pozzolanic material [18, 19].

It is true that silica fume significantly improves a number of properties in concrete. The main reason why it does this lies in two main facts. Firstly, its extremely fine size, and secondly, its pozzolanic activity. As to the first fact, the very fine size makes it possible for the particles of silica fume to adhere to the surfaces of aggregates far easier than cement particles. This results in filling up of the weakest part of concrete which is the interfacial zone. Moreover, it efficiently reduces or eliminates bleeding. Thus, it reduces porosity, especially around aggregates. Therefore, its use improves durability. The pozzolanic activity adds the benefit that the particles of silica fume react with the calcium hydroxide product of hydration to form calcium silicate hydrates. Thus adding to the strength of concrete especially in the zones where the concrete is weakest at the paste/aggregate interface.

Nevertheless, the use of silica fume should not exceed $10 \%$ of cement mass. Otherwise such use becomes counterproductive. Also the quantity of silica fume, if used, should not be less than $5 \%$ of the cement mass otherwise it becomes an inefficient, though expensive material. Therefore, the benefits reaped out of silica fume are in fact very much related to the presence of the aggregates. This conclusion has been confirmed when neat paste was subjected to testing with and without silica fume replacement [20]. If less than $5 \%$ is used, there would not be enough particles of the silica fume to cover the aggregates. If more than $10 \%$ is used, the pozzolanic reaction of silica fume would hinder the normal long term Portland cement hydration development due to the early pozzolanic reaction of silica fume that creates a barrier between the 'still not totally hydrated' cement particles [21].

At the same time, the use of silica fume nearly always necessitates the use of superplasticizer. This is because silica fume causes a large demand for water due to its large surface 
area. The superplasticizer effect was found to be enhanced by the silica fume inclusion to the extent that no additional water is needed and therefore, the workability is maintained at the same level of $w / c$ ratio with and without the silica fume [22].

Silica fume causes acceleration in the hydration process. This may result in increasing the heat produced [23]. The acceleration in hydration is further enhanced if there was a combination of silica fume and GGBFS (or GGBS) [24].

It is seen from this very brief presentation of silica fume, that its use can be enormously beneficial from the point of view of creating a durable concrete that possesses very low permeability. Yet, it is very important to note the limitations whereby such use should be constrained. Otherwise this use in itself may produce negative effects.

\section{Fly Ash}

This is a by-product of the coal fired power industry. The classification of fly ash as being type $\mathrm{F}$ or $\mathrm{C}$ depends upon the source of the coal. Generally type F comes from bituminous coal and contains high amount of silica. Type $\mathrm{C}$ fly ash is generally derived from sub-bituminous coal and lignite. Type $\mathrm{C}$ is usually rich in lime. Type $\mathrm{F}$ fly ash is the one that is most commonly used in concrete and is known to possess pozzolanic properties.

So far fly ash has been largely considered as a waste product. However, the attitude towards fly ash has shifted quite significantly from considering it a waste material toward considering it as a valuable asset. The reasons behind this important shift are greatly due to continuous research in the area of using this material as a cement replacement.

It has been proven that fly ash can improve workability and durability. Moreover, because of the improved workability, a lower water demand results in enhancing strength while using less cement and thus producing lower heat at hydration. The volume of research conducted on fly ash and its effects is enormous. It is also not free from contradictions and controversy. Yet, the overall picture that emerges is a positive one. Because of the increasingly positive image that emerges from the advantages of using fly ash, we can understand the push to use as much as possible of it. This trend has produced what is now called 'high volume fly ash replacement'. There is no doubt that if we can substitute cement by large amount of fly ash, we can achieve several environmental benefits. Obviously, one benefit is getting rid of the accumulating fly ash that can be a hazard if inhaled or if it contaminates the water table.

Investigations into the use of high volume class $\mathrm{F}$ fly ash together with low portland cement content have produced favorable results as far as strength and durability are concerned $[25,26]$. Malhotra has shown that up to $60 \%$ of the cement can be replaced by fly ash of class F or C and still give excellent strength and durability results [27]. It has been reported that high volume fly ash concrete showed exceptionally low permeability to water and chloride ions [28]. Ravina clearly illustrated that concretes with fly ash as partial replacement of sand have had higher compressive strength and modulus of elasticity than plain concretes without fly ash even when the portland cement content was $15 \%$ less than that of the concrete that contained no fly ash. $\mathrm{He}$ related the effects to the densification and microstructural modification of the hardened cement paste [29].

These research works are no doubt correct and very well conducted. However, we should not be tempted to choose their results out of context. We must not forget that a great deal of research occurs in ideal conditions of mixing, compaction and above all curing. This is absolutely understandable since we often want to scientifically study, analyse and compare several parameters. The problem is that in practice, things often happen quite differently. Curing is seldom done as desired, let alone being continued beyond 7 days. Research results on the effects of variation of temperature and humidity conditions during the initial curing period abound. They point to important differences in the behaviour of fly ash concrete between real and lab work.

The problem associated with fly ash is mainly due to its slow pozzolanic activity between the calcium hydroxide produced from the hydration of portland cement and alkali soluble silicates or "glass" content of fly ash [30]. At normal temperatures, the pozzolanic reaction is slow and no significant changes are observed after the initiation of hydration. To achieve the desired concrete properties studies [31] indicated prolonged moist curing to ensure adequate early strength development. However, some researchers [32] recommend initial curing of 7-days as a condition for the concrete blended with supplementary cementitious materials. While this recommendation is correct for commonly practiced concrete production including relatively low amounts of fly ash, it is wrong to try to extrapolate such recommendation to 'unusual' concrete like that with high volume fly ash content.

Results have recently been obtained from an extensive research conducted on high volume fly ash replacement concrete which was cured under conditions that resemble realistic circumstances in the Middle East [33]. The results point to the necessity of paying great deal of attention to the importance of prolonged curing if high volume fly ash is contemplated. If we take only half of the fact about the good effects of high volume fly ash replacement, we may easily end up with concrete with high permeability and where its steel reinforcement would corrode in a very short period. It has been shown that chloride penetration in concrete that contains more than $50 \%$ fly ash replacement is very significant [33]. In places where chloride contamination is expected, we need to be very cautious. This does not mean in any way that we should not go for high volume fly ash substitution. What we are saying is that when we do this, we must give a special treatment to this concrete especially in the processes of compaction and curing.

So, in relation to the topic of sustainability, we realize that the important issues are to:

1. use as little as possible of cement.

2. use as much as possible of fly ash instead of cement and where possible, instead of sand.

3. still be able to produce concrete that is durable for the design life of the structure. 
In effect, these are the issues that are most crucial in the sustainability quest of concrete production. The only way that may realize an optimization of these issues is through knowledge of the limitations of the material and the influences of local practices. And the only way of applying such knowledge is through engineers on the job who have been very well trained and have become very much aware of the necessity of accommodating the particularities of the materials and working and environmental conditions.

\section{GGBFS}

Ground Granulated Blast Furnace Slag (GGBFS or BFS) is a by-product of the steel industry. The BFS is a latent hydraulic material which has chemical composition intermediate between that of pozzolanic material and Portland cement. The BFS acts as hydraulic cement when mixed with water in the presence of OPC. BFS is being used in the construction of dams and massive projects because of its low heat of hydration. Wet Sleddale Dam in Cumbria was constructed with $70 \%$ replacement of cement by BFS in the year 1966. After 35 years of exposure to acidic environment, the dam continues to perform extremely satisfactorily [34]. BFS was also used in the marine project in the construction of the causeway linking the two nations of Saudi Arabia and Bahrain with $72 \%$ replacement of cement by BFS and it has been performing satisfactorily [35].

Again, studies abound when it comes to the effects of BFS replacing cement. There is no doubt that great benefits can be reaped as far as the quality of the concrete when BFS is used. This is apart from the obvious benefits that result from using less cement. And again, the importance of giving due consideration to the particularities of the place, the structure, work force abilities and the environment can not be too much emphasized.

\section{Metakaolin}

Metakaolin is produced by calcining kaolinite clays. This results in highly active pozzolanic material that has been found useful as a cement replacement and concrete property enhancer [36]. As noted in the discussion of silica fume, fly ash and BFS, the use of metakaolin also requires careful consideration as to limitations of quantity and efficient utilisation [37].

\section{Rice Husk Ash}

Rice husk ash has been used in concrete in its capacity as a filler and as a pozzolanic material. Its potential as a partial replacement of cement has been examined and research abounds pointing to advantages and limitations [38, 39].

\section{USING NON-LIMESTONE BASED CEMENTS}

\section{Magnesia Based Cement}

Quite recently, there have been attempts to produce cement based on magnesium carbonates rather than calcium carbonates. Such a development may result in halving the $\mathrm{CO}_{2}$ emission caused by portland cement production [40]. Of course, such move may require mining of magnesites and adapting the existing plants to meet necessary methods to produce the new product. Research is continuing on this and similar alternative products.

\section{Replacements to Natural Aggregates}

The aggregates constitute the major bulk of concrete. The concrete industry, in general, does not show a great deal of concern regarding the availability of aggregates. Yet, studies in various parts of the world have started to appear and point to the increasing scarcity of the material [41, 42]. Added to this, much of the landscape in developed and developing countries is being scarred as a result of quarrying for aggregates. In Kuwait, natural aggregates are of excellent quality, yet a 1984 study has warned of their eminent depletion [43]. Nevertheless, concrete structures in the Middle East that were constructed using excellent aggregates did not escape a rapid deterioration. It can be foreseen that when countries like Kuwait and her neighbours, which witness today an unprecedented phenomenon in building boom, experience shortages in good quality aggregates, inferior material will be used instead. When we further add to this, the rush for completion due to various reasons, we can expect the deterioration phenomenon to manifest on a very large scale. Repairs and reconstruction mean further consumption of raw materials, further consumption of cement and further emission of green house gases.

It is thus understandable that a comprehensive treatment of the issue of concrete materials must include protection from deterioration. This also means that the aggregates which make up the bulk of concrete must be of good quality.

There has been quite a strong movement towards using alternatives for natural materials, and rightly so. Recycled crushed concrete, crushed bricks and blocks, bottom ash, blast furnace slag, and a large range of natural and artificial lightweight aggregates are now available. In the context of our discussion here, such alternatives should be assessed according to the situation at hand. Nevertheless, researchers still need to evaluate the durability performance of each type of aggregates so as to provide the industry with the necessary information that helps in making decisions concerning materials use.

\section{The New Concretes}

Several new innovative concrete related products have appeared quite recently. Some of these products are already sustainability motivated. Some other products, though have not been invented with sustainability as criterion, do have a positive impact on sustainability. Also there are some products that were invented with the aim of producing ultra high strength concrete. These solve many problems in construction and add a wealth to architectural possibilities. Nevertheless all such products need to be carefully evaluated from the sustainability view point. In the following paragraphs, we will try to summarise recent developments in this regard.

\section{Reactive Powder Concrete (RPC)}

Though the idea was not totally new, Richard and Cheyrezy were able in 1995 to present a fully structured and cohesive description of Reactive Powder Concrete as completely new breakthrough in concrete production [44]. This concrete describes a family of ultra high strength concretes that range in compressive strength from $170 \mathrm{MPa}$ to more than $800 \mathrm{MPa}$. The flexural strength ranges from 30 to 140 $\mathrm{MPa}$. Briefly, these concretes depend upon elimination of the 
skeletal structure of concrete that comprises the large aggregates and sand. Instead, they employ extra fine sand and crushed quartz together with silica fume and superplasticizer. This technology makes it possible for the fine constituents to fill, as much as possible, the available space without being bound and hindered by a skeletal structure that contains pores which can never be filled. The making of such concrete may also involve application of pressure and or heat. Furthermore, incorporation of fine steel fibres may be utilized to further enhance strength and ductility.

It is evident that such concrete can revolutionize the concrete building industry. Without trying to be exclusive, this concrete would produce much smaller sections, eliminate steel reinforcement, enhance durability and may end up costing less in spite of its high initial cost. Obviously, concrete of this sort lends itself more readily to the processes of precasting.

Elimination of steel bar reinforcement and utilizing precasting procedures would no doubt significantly reduce deterioration problems mainly due to corrosion of reinforcement and the strict methods of production. Using thinner sections and lighter construction, result in less cement needed, lower dead loads, shallower foundations, larger usable spaces and more elegant structures. Elimination of large aggregates solves aggregate shortage problems in many locations. All these effects are positive from the point of sustainability.

The production and use of this type of concrete in the Middle East can definitely be a viable option. We are not saying it should be the only option. But, we believe that the initial high cost of producing this concrete would be compensated for by having a durable construction in this fast growing part of the world.

\section{Geopolymers}

It seems that we owe a great deal of our cement and concrete heritage today to ancient Romans [15] and even to earlier people in Mesopotamia [45]. Not only they discovered pozzolanic materials, but also they found the way to activate it simply by mixing it with slaked lime [15]. Doing so, they actually produced concrete with extraordinary excellent durability. We are nowadays revisiting their work and reinventing it.

Geopolymers is a commonly used name for alkaliactivated cements. Simply, it has been found that the addition of alkalis like calcium hydroxide, sodium hydroxide or potassium hydroxide to fly ash activates the material and accelerates the pozzolanic reaction. The result is an amorphous aluminosilicate gel whose structure has the ability to absorb and lock potentially deleterious ions [46] and also can resist volume changes [47].

We here, have only very lightly touched on the subject of geopolymers. However, in the context of this paper, it suffices to say that fly ash when activated in this manner can produce a hardened paste that possesses mechanical strength of nearly $60 \mathrm{MPa}$. It is only sufficient to remember, that fly ash production is around $800 \mathrm{Mt}$ per year [48]. Development of this sort has the potential of: (a) providing a large consumption outlet for fly ash, (b) making concrete from less and less cement, and (c) producing much more durable concrete.

Having said so, it is not a matter of simply bringing materials and mixing them together to produce the desired results. We need to combine experimentation, chemical knowledge, further research into crystalline formations and developments resulting from such activation, long term research into possible effects of variation in temperature and humidity on durability, volume changes and mechanical properties. But very importantly, engineers and researchers need to be aware of the problems that a concrete structure is likely to face in order that the solution offered meets the required performance.

\section{Concrete-Polymer-Composites}

Advances in polymer development and uses are immense. It has been forecast that within 15 years, polymers in construction will be the most important element in polymer production and market [49]. This is however, a typical case of the need for the co-operation and thorough understanding of the situation in which such materials may be used. Knowledge of the properties and differences between various types is necessary before employing materials of this sort. Promises of the marketing agencies are not enough and can not replace scientific understanding of the properties and their suitability for the situation at hand. A wise use of these composites has the potential of saving substantial cost to the industry and the nation. This is because these materials can protect from serious deterioration and thus are invaluable in the quest for sustainable construction industry.

\section{OTHER DEVELOPMENTS AND MATERIALS}

In the following paragraph, we will attempt to very briefly describe some other developments that carry promise as far as sustainability is concerned.

\section{Self Compacting Concrete (SCC)}

This is a new generation in the concrete family. The importance of producing very low w/c paste with self compaction property has been presented since the superplasticizers made the pronounced impact on the concrete industry [50]. The technology has taken off more significantly in the 90's and is now becoming a very popular method [51]. Briefly, the technology employs the use of fillers and potent superplasticizers as in the case of high performance concretes. But in addition, it uses specifically viscosity enhancing admixtures and may use air entraining agents as well. The resulting concrete is that which flows freely and needs no compaction. It can be easily appreciated that such concrete is an excellent solution for modern high rise buildings that need pumping the concrete during construction. Moreover, due to the dispensability of compaction, cost savings and noise elimination have resulted in substantial gains economically and environmentally. This technique has also produced uniformity of concrete elements in addition to excellent durability. This development therefore, is rightly considered a valuable contribution to sustainable industry. It has also enhanced the synergetic research in what has been called "smart admixtures" which produce the desired behaviour in the composite material. 


\section{New Generation of Lightweight Aggregates}

Very recently manufacturing lightweight aggregates from fly ash has gained another step forward in the development of aggregates that possess excellent adhering properties with the paste matrix. This aggregate, produced concrete of high performance which exceeded that of concrete made with granite or other natural aggregates and contains equal amount of cement [52]. This has dispelled the previously held belief that connects strength with high density. It can be realized that advances in this respect are quite promising in getting rid of fly ash accumulation while producing lighter, stronger and more durable structures.

\section{CONCLUSIONS}

1. Durability of concrete is one of the most important factors, if not the most important, in the attempt to arrive to sustainable stage in concrete construction.

2. Cement manufacture is a major contributor to the green house gases. Efforts should be directed to reduce the need for this manufacture.

3. Alternative materials that may replace cement include industrial by-products like silica fume, fly ash and blast furnace slag. All of these carry enormous benefits to the concrete industry in general and sustainability in particular.

4. Extracting natural aggregates for the concrete industry can not be sustainable in the long run. Recycling aggregates, crushed bricks, crushed blocks, crushed concrete and lightweight aggregates made from waste products are alternatives that should be given due importance.

5. New polymer materials that serve to create concrete polymer composites carry the promise to become major building materials in the future. Such materials provide solutions to durability issues especially when used in repair and pre-cast industries. Though may be expensive, their use may prove to be one good solution to the issue of sustainable building.

6. Looking beyond the current culture in concrete should be researched and discussed. This is now possible with the advent of new materials that allow very strong composites to be produced. In view of these new developments, can the tradition of reinforcement be revisited?

7. Academics and engineers need to realize the importance of sustainability. Revision to programmes in civil engineering should, in the opinion of these authors, be done to include sustainability as an important part of materials study as well as design.

8. The developments in new materials put emphasis on the necessity to deeply understand the functions and limitations of any new suggested material that is being marketed for the use in concrete. This again highlights the need for revisiting civil engineering courses of the structures stream in order to include deeper study and appreciation of the chemical and physical characteristics of materials of construction.

\section{REFERENCES}

[1] P.-C. Aitcin, "Cements of yesterday and today: Concrete of tomorrow," Cement and Concrete Research, vol. 30, pp. 1349-1359, 2000.

[2] E. Gartner, "Industrially interesting approaches to "low-CO2" cements," Cement and Concrete Research H. F. W. Taylor Commemorative Issue, vol. 34, pp. 1489-1498, 2004.

[3] B. Scheubel and W. Nachtwey, "Development of Cement Technology and its Influence on the Refractory Kiln Lining," presented at Refra Kolloquium, Berlin, 1997.

[4] Anon., "UAE industry entering transitional phase," Albawaba Media and Technology Group, report No. 204326, 2006, [Online] Available;

http://www.menareport.com/en/business,Industry/204326 [accessed April 24, 2008].

[5] Anon.,"Dh1.5 billion cement plant to be set up," in Khaleej Times. Dubai, 2006, [Online] Available; http://www.hamriyahfz.com/en/ news/default.asp?id=38 [Accessed 24, April 2008].

[6] Anon., "GCC Equity Research, Fujairah Cement Industries Co.," 2006, [Online] Available; www.taib.com/reports/E01025081006/ EQ_FCI.AD_AUG06.pdf, [Accessed 24, April 2008]

[7] Strategic Industry Leaders, Punching Above Its Weight, Department of Industry, Tourism and Resources, Canberra, 2006.

[8] V. M. Malhotra, "Role of Supplementary Cementing Materials in Reducing Greenhouse Gas Emissions," presented at Infrastructure Regeneration and Rehabilitation Improving the Quality of Life through Better Construction, A Vision for the Next Millenium, Sheffield, 1999.

[9] Anon., "Co2 emissions from cement manufacture have been undersetimated," Applied Catalysis B: Environmental, vol. 13, pp. N12N13, 1997.

[10] C. A. Hendriks, E. Worrell, L. Price, et al. "Emission reduction of greenhouse gases from cement industry," presented at 4th International Conference on Greenhouse gas control technologies, Interlaken, Austria, 1998.

[11] The United Kingdom Parliament, "Supplementary Memorandum by the British Cement Association," London 2002.

[12] ECOSECURITIES, "Global Climate Change: Risk to Bank Loans," ECO Securities-United Nations Environment Programme Finance Initiative, New York, Report 20052005.

[13] J. P. Holdren, "U.S. Climate Policy Post Kyoto," presented at The Convergence of U.S. National Security and the Global Environment, 2003.

[14] W. T. Choate, "Energy and Emission Reduction Opportunities for the Cement Industry," Columbia 2003.

[15] B. Herring and S. Miller, "The Secrets of Roman Concrete," Constructor, pp. 13-16, 2002.

[16] B. Mather, "Use Less Cement," Concrete International, vol. 2, pp. 22-24, 1980.

[17] B. Mather, "Use Less Cement," Concrete International, vol. 22, pp. 55-56, 2000.

[18] ACI Committee 234, Guide for the Use of Silica Fume in Concrete, Report ACI 234R-6, American Concrete Institute Publication, pp. $1-63,2006$.

[19] M. D. Luther, "High-performance silica fume (microsilica) - Modified cementitious repair materials," presented at 69th annual meeting of the Transportation Research Board, 1990.

[20] K. L. Scrivener, A. Bentur and P. L. Pratt, "Quantitative characterizationof the transition zone in high strength concretes," Advances in Cement Research, vol. 1, pp. 230-237, 1988.

[21] R. D. Hooton, "Influence of silica fumereplacement of cement on physical properties and resistance to sulphate attack, freezing and thawing, and alkali-silica reactivity," ACI Materials Journal, vol. 90, pp. 143-151, 1993.

[22] J. P. Ollivier, A. Carles-Gibergues and B. Hanna, "Activite' pozzolanique et actionde remplissage d'une fumee de silica dans les matrices de beton de haute resistance," Cement \& Concrete Research, vol. 18, pp. 438-448, 1988.

[23] D. M. Roy, "Hydration of blended cements containing slag, fly ash, or silica fume," presented at Meeting of Institute of Concrete Technology, Coventry, UK, 1987. 
[24] J. A. Larbi, A. L. A. Fraay, and J. M. J. M. Bijen, "The chemistry of the pore fluid of silica fume-blended cement systems," Cement \& Concrete Research, vol. 20, pp. 506-516, 1990.

[25] W. S. Langley, G. G. Carette, and V. M. Malhotra, "Structural concrete incorporating high volumes of ASTM Class F fly ash," ACI Materials Journal (American Concrete Institute), vol. 86, pp. 507-514, 1989.

[26] C. S. Poon, L. Lam, and Y. L. Wong, "Study on high strength concrete prepared with large volumes of low calcium fly ash," Cement and Concrete Research, vol. 30, pp. 447-455, 2000.

[27] V. M. Malhotra, "CANMET investigations dealing with highvolume fly ash concrete," in Advances in Concrete Technology, V. M. Malhotra, Ed. Ottawa, Canada: CANMET, 1994, pp. 445-482.

[28] P. K. Mehta, "Advancements in concrete technology," Concrete International, vol. 21, pp. 69-76, 1999.

[29] D. Ravina, "Mechanical properties of structural concrete incorporating a high volume of class $\mathrm{F}$ fly ash as partial fine sand replacement," Materials and Structures, vol. 31, pp. 84-90, 1998.

[30] P. L. Owens, "Fly ash and its usage in Concrete," Concrete, vol. 13, pp. 21-26, 1979.

[31] O. S. B. Al-Amoudi, Rasheeduzzafar and M. Maslehuddin, "A Reply to a Discussion by M.N. Haque and O.A. Kayyali of the Paper "Carbonation and Corrosion of Rebars in Salt Contaminated OPC/PFA Concrete"," Cement and Concrete Research, vol. 21, pp. 956-957, 1991.

[32] M. N. Haque, "Give it a Week - 7 days Initial Curing," Concrete International, vol. 20, pp. 45-48, 1998.

[33] M. S. Ahmed, O. Kayali, and W. Anderson, "Chloride Penetration in Binary and Ternary Blended Cement Concretes as Measured by Two Different Rapid Methods," Cement \& Concrete Composites, vol. in press, pp. doi:10.1016/j.cemconcomp.2008.02.005, 2008.

[34] M. Connell, "The Long-Term Performance of High Slag Concrete," Concrete, vol. 32, pp. 30-31, 1998.

[35] L. C. F. Ingerslev, "Precast Concrete for the Bahrain Causeway," Concrete International, vol. 11, pp. 15-20, 1989.

[36] B. B. Sabir, S. Wild, and J. Bai, "Metakaolin and Calcined Clays as Pozzolans for Concrete: A Review," Cement and Concrete Composites vol. 23, pp. 441-454, 2001.

[37] J. M. Khatib and O. Kayali, "Dimensional Stability And Strength Of Metakaolin Mortar, Proceedings of the International Conference: Concrete Platform'07, 19-20 April, 2007, M. Russell and M. Basheer Ed., Queen's University Belfast Publication, ISBN 978-085389-913-6, Belfast, Ireland, pp. 357-364, 2007.
[38] R. Jauberthie, F. Rendell, S. Tamba and I. Cisse, "Origin Of The Pozzolanic Effect Of Rice Husks," Construction and Building Materials, vol. 14, pp. 419-423, 2000.

[39] V. Saraswathy and H. W. Song, "Corrosion Performance Of Rice Husk Ash Blended Concrete," Construction and Building Materials, vol. 21, pp. 1779-1784, 2007.

[40] O. Dyer, "A Rock And A Hard Place; Eco-Cement Yet To Cover Ground In The Building Industry," in The Guardian. London, 2003.

[41] O. Vagt, "Mineral Aggregates", Canadian Minerals Yearbook, Chapter 34, pp. 34.1-34.9, Natural Resources Canada, 1998.

[42] Anon., "world construction aggregates," T. F. Group, Ed., 2003.

[43] O. A. Kayyali, "Study of Aggregates used for concrete in Kuwait," Trasportation Research Record, pp. 26-33, 1984.

[44] P. Richard and M. Cheyrezy, "Composition of Reactive Powder Concrete," Cement and Concrete Research, vol. 25, pp. 1501-1511, 1995.

[45] D. M. Roy, "Alkali-activated cements Opportunities and challenges," Cement and Concrete Research, vol. 29, pp. 249-254, 1999.

[46] N. Quanlin and F. Naiqian, "Effect of modified zeolite on the expansion of alkaline silica reaction," Cement and Concrete Research, vol. 35, pp. 1784-1788, 2005.

[47] A. Palomo, M. W. Grutzeck, and M. T. Blanco, "Alkali-activated fly ashes: A cement for the future," Cement and Concrete Research, vol. 29, pp. 1323-1329, 1999.

[48] A. Fernandez-Jimenez and A. Palomo, "Composition and microstructure of alkali activated fly ash binder: Effect of the activator," Cement and Concrete Research, vol. 35, pp. 1984-1992, 2005.

[49] D. Van Gemert, L. Czarnecki, M. Maultzsch, et al. "Cement concrete and concrete-polymer composites: Two merging worlds: A report from 11th ICPIC Congress in Berlin, 2004," Cement and Concrete Composites, vol. 27, pp. 926-933, 2005.

[50] S. Diamond and C. Gomez-Toledo, "Consistency, setting, and strength gain characteristics of a "low porosity" Portland cement paste," Cement and Concrete Research, vol. 8, pp. 613-621, 1978.

[51] B. Persson, "A comparison between mechanical properties of selfcompacting concrete and the corresponding properties of normal concrete," Cement and Concrete Research, vol. 31, pp. 193-198, 2001.

[52] O. Kayali, "Fly Ash Lightweight Aggregates in High Performance Concrete," Construction and Building Materials, vol. in press, pp. doi:10.1016/j.conbuildmat.2007.09.001, 2007.

(C) Kayali et al.; Licensee Bentham Open.

This is an open access article distributed under the terms of the Creative Commons Attribution License (http://creativecommons.org/licenses/by/2.5/), which permits unrestrictive use, distribution, and reproduction in any medium, provided the original work is properly cited. 